\title{
Effect of Acute Hypercapnia on Renal and Proximal Tubular Total Carbon Dioxide Reabsorption in the Acetazolamide-treated Rat
}

Joseph Winaver, Kathleen A. Walker, and Robert T. Kunau, Jr.

Department of Medicine, The University of Texas Health Science Center, San Antonio, Texas 78284

\begin{abstract}
The present study evaluates the effect of acute hypercapnia on renal total $\mathrm{CO}_{2}\left(\mathrm{CCO}_{2}\right)$ reabsorption after inhibition of renal carbonic anhydrase.

Simultaneous renal clearance studies and free-flow micropuncture studies of the superficial proximal tubule were performed on plasma-repleted Sprague-Dawley rats treated with acetazolamide, $50 \mathrm{mg} / \mathrm{kg}$ body weight. Acute hypercapnia (arterial $\mathrm{PCO}_{2}, 120 \mathrm{mmHg}$; blood $\left.\mathrm{pH}, 7.02\right)$ was induced by ventilation with a $10 \% \mathrm{CO}_{2}-90 \% \mathrm{O}_{2}$ gas mixture. Control rats $\mathrm{PCO}_{2}$, $49.5 \mathrm{mmHg}, \mathrm{pH} 7.34)$ were ventilated with room air. The renal fractional excretion of $\mathrm{CCO}_{2}$ was $\sim 20 \%$ lower in the hypercapnic group compared with the rats given acetazolamide alone. Acute hypercapnia reduced the fractional delivery of $\mathrm{tCO}_{2}$ to the late proximal tubule by a comparable amount. The absolute proximal reabsorption of $\mathrm{CO}_{2}$ was increased by hypercapnia to $410 \pm 47$ vs. $170 \pm 74 \mathrm{pmol} \cdot \mathrm{min}^{-1}, P<0.05$. The single nephron glomerular filtration rate was $32.6 \pm 0.7 \mathrm{nl} \cdot \mathrm{min}^{-1}$ in the hypercapnic group and $43.8 \pm 1.7 \mathrm{nl} \cdot \mathrm{min}^{-1}$ in the rats given acetazolamide only, $P<0.01$.

Acute hypercapnia enhances renal sympathetic nerve activity. To eliminate this effect, additional experiments were performed in which the experimental kidney was denervated before study. Denervation prevented the change in the single nephron filtration rate during acute hypercapnia, but absolute and fractional proximal $\mathrm{tCO}_{2}$ reabsorption remained elevated in comparison to denervated controls.

The concentration of $\mathrm{H}_{2} \mathrm{CO}_{3}$ in the late proximal tubule, calculated from the measured luminal $\mathrm{pH}$ and bicarbonate concentration and the estimated cortical $\mathrm{PCO}_{2}$, was higher in the hypercapnic group, which was a finding compatible with $\mathrm{H}_{2} \mathrm{CO}_{3}$ cycling from lumen into proximal tubular cell, which provided a source of hydrogen ions for secretion.
\end{abstract}

\section{Introduction}

Arterial blood $\mathrm{CO}_{2}$ tension $\left(\mathrm{PCO}_{2}\right)$ is considered to be one of the major factors regulating the rate of tubular hydrogen ion $\left(\mathrm{H}^{+}\right)$ secretion (1). Many clearance studies have documented that

Parts of this study were presented at the 16th annual meeting of the American Society of Nephrology, Washington, DC, 1983.

Address reprint requests to Dr. Kunau. Dr. Winaver's present address is the Faculty of Medicine, Rappaport Family Institute for Medical Research, Haifa, Israel.

Received for publication 24 October 1984 and in revised form 17 October 1985.

1. Abbreviations used in this paper: ACTZ, acetazolamide; AHC, acute hypercapnia; DNX, denervated; FE, fractional excretion; GFR, glomer-

J. Clin. Invest.

(C) The American Society for Clinical Investigation, Inc.

0021-9738/86/02/0465/09 \$1.00

Volume 77, February 1986, 465-473 acute hypercapnia (AHC) ${ }^{1}$ enhances the maximal bicarbonate reabsorptive capacity of the kidney and decreases fractional bicarbonate excretion (2-5). It has also been shown that AHC can augment renal bicarbonate reabsorption in the presence of pharmacologic inhibitors of renal carbonic anhydrase such as acetazolamide (ACTZ). Thus, it has been suggested that carbonic anhydrase independent bicarbonate reabsorption is stimulated by hypercapnia (5-7).

Rector (8) has argued that, in the absence of carbonic anhydrase, the uncatalyzed rate of $\mathrm{CO}_{2}$ hydration or hydroxylation cannot supply sufficient $\mathrm{H}^{+}$to account for all of the bicarbonate reabsorbed under these circumstances. A number of possible means have been suggested as being responsible for maintenance of $\mathrm{H}^{+}$secretion after inhibition of carbonic anhydrase. Of several possible mechanisms, recent studies have been interpreted to suggest that cycling of carbonic acid $\left(\mathrm{H}_{2} \mathrm{CO}_{3}\right)$ from lumen into cell is a means by which $\mathrm{H}^{+}$may be continuously made available for secretion in the proximal tubule of the ACTZ-treated rat under control circumstances and after the induction of metabolic acidosis or alkalosis (9).

In addition to a variety of systemic effects, AHC can reduce the glomerular filtration rate (GFR) and renal blood flow (1014). The reduction in renal blood flow noted after AHC can be abolished by renal denervation, but not by maneuvers that block renin production (14). These findings suggest that the change in renal hemodynamics after AHC is related to increased renal sympathetic nerve activity. The findings of Anderson et al. (14) also suggest that the reduction in renal blood flow after AHC is proportionately greater than the change in the GFR. As a consequence, the filtration fraction and the peritubular capillary protein concentration are both increased. Recently, Cogan et al. (15) have demonstrated that proximal total $\mathrm{CO}_{2}\left(\mathrm{tCO}_{2}\right)$ reabsorption during inhibition of carbonic anhydrase may be modified by the peritubular protein concentration (15). Thus, any increase in proximal $\mathrm{tCO}_{2}$ reabsorption after AHC in the ACTZtreated rat may, at least in part, be an indirect result of the change in peritubular protein concentration.

In addition to the above observations, Shah et al. (16) and Chan (17) have shown that alpha adrenergic stimulation increases and denervation reduces proximal bicarbonate reabsorption. Thus, AHC may result in an increase in renal bicarbonate reabsorption via a direct effect of the AHC per se at the tubular level or as a consequence of stimulation of renal sympathetic nerve activity.

The present free flow micropuncture and clearance studies were undertaken to evaluate the effect of $\mathrm{AHC}$ on renal and proximal tubular $\mathrm{tCO}_{2}$ reabsorption in the ACTZ-treated rat, and to examine the potential contribution of the increased sympathetic nervous activity induced by $\mathrm{AHC}$ on $\mathrm{tCO}_{2}$ reabsorption under these conditions.

ular filtration rate; SNGFR, single nephron glomerular filtration rate; $t \mathrm{tO}_{2}$, total $\mathrm{CO}_{2}$; TF, tubular fluid; $\mathrm{TF} / \mathrm{P}$, tubular fluid to plasma ratio; $\mathrm{U} / \mathrm{P}$, urine to plasma ratio. 


\section{Methods}

25 Sprague-Dawley rats weighing $300-360 \mathrm{~g}$ were studied in four experimental groups. The rats were fed a standard rat chow diet and had free access to food and water before the experiments.

Anesthesia was induced by Inactin $(100 \mathrm{mg} / \mathrm{kg}$ body weight, BYK Guldens, Konstanz, Federal Republic of Germany). The animals were placed on a thermostatically controlled heated table and body temperature was maintained between $37^{\circ}$ and $38^{\circ} \mathrm{C}$. Polyethylene catheters (PE 50) were inserted into the right femoral vein and artery for infusion of the various solutions and for blood pressure monitoring and sampling of arterial blood, respectively.

A tracheostomy was performed and the animals were connected to a Harvard rodent respirator. The rate and depth of ventilation were adjusted so as to keep arterial blood $\mathrm{PCO}_{2}$ between 40 and $50 \mathrm{mmHg}$ in the control animals ventilated with room air in the presence of ACTZ (groups $\mathrm{A}$ and $\mathrm{D}$ ). AHC was induced in groups $\mathrm{B}$ and $\mathrm{C}$ by connecting the ventilator to a $10 \% \mathrm{CO}_{2}, 90 \% \mathrm{O}_{2}$ gas mixture.

All animals were infused with homologous isooncotic plasma obtained on the same day from another Sprague-Dawley rat. The plasma was infused from the start of the experiment at a rate of $20 \mu \mathrm{l} / \mathrm{min}$. This amount of plasma resulted in a hematocrit at the conclusion of the study that was similar to that obtained before the abdominal and neck surgery. In addition, the rats received a noncolloid solution, either a modified Ringer solution $\left(\mathrm{NaCl}, 115 \mathrm{meq} / \mathrm{liter} ; \mathrm{NaHCO}_{3}, 25 \mathrm{meq} / \mathrm{liter}, \mathrm{KCl}, 4\right.$ meq/liter) in normocapnic animals (groups $A$ and $D$ ) or normal saline $(0.9 \% \mathrm{NaCl})$ in the hypercapnic animals (groups $\mathrm{B}$ and $\mathrm{C}$ ). These solutions were given at a rate of $25 \mu \mathrm{l} / \mathrm{min}$ simultaneously with the plasma infusion. Normal saline rather than Ringer's solution was administered to the hypercapnic animals to minimize the increase in plasma bicarbonate level induced by the hypercapnia, thus reducing the variability in filtered load among the experimental groups (15). An indwelling polyethelene catheter was inserted into the bladder for collection of the bladder urine in groups $A$ and $B$. The clearance data reported for these groups represent the findings from both kidneys. In groups $\mathrm{C}$ and $\mathrm{D}$, where denervation of the left kidney was performed, urine was collected separately from each kidney.

Micropuncture protocol. A ventral abdominal approach was used to expose the left kidney for micropuncture. Care was taken to minimize blood loss during the surgical preparation by clamping the bleeding points. The left kidney was separated from the surrounding tissue after ligation of the adrenal vessels. The kidney was placed in a lucite cup surrounded by oil-soaked cotton and bathed with mineral oil bubbled continuously with $5 \% \mathrm{CO}_{2}$ gas and maintained at $37^{\circ}$ to $38^{\circ} \mathrm{C}$. An arterial blood pressure of $100 \mathrm{mmHg}$ or less at this point led to the exclusion of the animal from further study.

After completion of surgical preparation, a loading dose of $240 \mu \mathrm{Ci}$ ${ }^{3} \mathrm{H}$-methoxy inulin (New England Nuclear, Boston, MA) was given as a bolus followed by a sustaining infusion of the same amount per hour in the noncolloid solutions listed above. $30 \mathrm{~min}$ after the initiation of the inulin infusion, the modified Ringer solution was discontinued and $\mathrm{ACTZ}, 50 \mathrm{mg} / \mathrm{kg}$ body weight, was given as a bolus injection followed by a continuous infusion of the same amount per hour. ACTZ was dissolved in a $300 \mathrm{mM} \mathrm{NaHCO}$ solution and was given at a rate of $25 \mu \mathrm{l} /$ min in this solution in groups $A$ and $D$ to prevent reduction in plasma bicarbonate level due to ACTZ-induced urinary losses of bicarbonate. In the hypercapnic animals, groups B and C, ACTZ was dissolved in 50 $\mu 1$ of $300 \mathrm{mM} \mathrm{NaHCO}$ solution and then mixed with $3 \mathrm{ml}$ of saline solution and infused at a rate of $25 \mu \mathrm{l} / \mathrm{min}$. Replacement of urinary losses of bicarbonate was not necessary in groups B and C.

30 min after ACTZ was begun, an arterial blood sample of $400 \mu \mathrm{l}$ was taken for determination of $\mathrm{pH}$ and $\mathrm{tCO}_{2}$, and a urine collection was begun into tared vials under mineral oil. A second blood sample was obtained at the end of the experiment. 4-6 late proximal convoluted tubules were identified by intratubular injection of $0.3 \%$ FD\&C solution (Keystone Aniline \& Chemical Co., Chicago, IL) with sharpened micropipettes (5-6 $\mu \mathrm{m}$ OD).
The following experimental groups were studied:

(a) Group $\mathrm{A}(n=7), \mathrm{ACTZ}$, and normal $\mathrm{PCO}_{2}$. This experimental group was ventilated with room air. Plasma $\mathrm{PCO}_{2}$ was maintained between 40 and $50 \mathrm{mmHg}$ by appropriate adjustment of the respirator. 4-6 timed tubular fluid collections were obtained from late proximal convoluted tubules by sharpened glass micropipettes (10-11 $\mu \mathrm{m}$ OD). Samples were immediately transferred to a chamber containing water-equilibrated mineral oil diffused with a $10 \% \mathrm{CO}_{2}, 90 \% \mathrm{O}_{2}$ gas mixture and kept there until analysis. A simultaneous urine collection was obtained during the micropuncture period for clearance data.

(b) Group $B(n=7)$ and $A C T Z$ plus $A H C$. This group was ventilated with $10 \% \mathrm{CO}_{2}, 90 \% \mathrm{O}_{2}$ gas mixture during the experiment. Late proximal tubular samples and urine were obtained as in group A. The samplecontaining pipettes were transferred to an oil chamber as in group A, with the exception that $15 \% \mathrm{CO}_{2}$ was in the chamber.

(c) Group $C(n=6), A C T Z$ plus AHC and denervation. This experimental group was treated identically to group B with the following exceptions: after separation of the left kidney from the surrounding tissue, a polyethylene catheter was inserted into the left ureter. Renal denervation was then performed according to the method described by Bello-Reuss and Gottschalk (18). The renal artery was exposed and the adventitia was stripped. The renal nerves were dissected and cut free. The renal artery was then wrapped with a narrow band of filter paper, previously soaked in a solution of $90 \%$ alcohol, $10 \%$ phenol, for 20-30 min. Care was taken to prevent contact between the phenol solution and the surface of the kidney during the procedure. Tubular samples were obtained as in the previous group. Urine was collected separately from the denervated (DNX) left kidney and the untouched right kidney.

(d) Group D $(n=5), A C T Z$, normal $\mathrm{PCO}_{2}$, and denervation. This group served as a control for group $C$ to evaluate the effect of DNX per se on bicarbonate transport in the presence of ACTZ. The animals were ventilated as in group A with room air. Denervation was performed as described in group $C$. Tubular samples were obtained as previously described.

To evaluate the effectiveness of the denervation procedure, a separate group of eight rats was studied. Four rats underwent the denervation procedure as described for groups $C$ and $D$, and four rats were sham operated. $72 \mathrm{~h}$ later the kidneys were removed and placed immediately in dry ice. Tissue norepinephrine content was subsequently determined (19). Three of the four denervated kidneys had undetectable levels of norepinephrine. The fourth contained $30 \mathrm{ng} / \mathrm{g}$ kidney. The norepinephrine levels in the sham-operated kidneys were $250,365,411$, and 376 $\mathrm{ng} / \mathrm{g}$. We conclude that the denervation procedure used was successful.

In a separate series of studies, in rats prepared as in groups $C$ and $D$, the intratubular $\mathrm{pH}$ was measured with a micro (7-9 $\mu \mathrm{m}$ OD) $\mathrm{pH}$ electrode. The electrode was manufactured as described by Puacacco and Carter (20) with the exception that the $\mathrm{UO}_{2}$ content was reduced from 4 to $2 \%$. No electrode was used that did not have a slope of at least 58 $\mathrm{mV} / \mathrm{pH}$ unit when determined in vitro in a series of standard phosphate

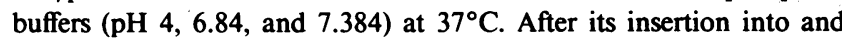
removal from the tubule, the electrode was again tested in vitro. If the electrode potential deviated by $>2 \mathrm{mV}$ from the value obtained before tubular puncture, the data were discarded. The $\mathrm{pH}$ electrode was connected to a model 616 digital electrometer (input resistance $2 \times 10^{14} \Omega$ ) (Keithley Instruments, Inc., Cleveland, $\mathrm{OH}$ ) through an $\mathrm{Ag} / \mathrm{AgCl}$ half cell (WPI, New Haven, CT). The electrometer was connected to a 7132A thermal recorder (Hewlett-Packard Co., San Diego, CA). This arrangement permitted us to read the potential of the electrode by the digital readout of the electrometer, yet graphically observe the characteristics and time course of the electrode response on the chart recorder. A calomel reference electrode, connected to the low input of the electrometer, and the cut end of the rat's tail were placed into a beaker containing Ringer's solution.

These micro $\mathrm{pH}$ electrodes can achieve values within 1 to $2 \mathrm{mV}$ of end point in 20-30 s after placement in the pH buffers. When used in the tubular lumen, a stable reading, i.e., a variation of $1 \mathrm{mV}$ or less, for $1 \mathrm{~min}$, was recorded before the electrode was withdrawn. The $\mathrm{pH}$ mea- 
surements were made in late proximal sites located as described above. Two measurements were made in each of six rats.

Analysis. The volume of each tubular fluid sample was determined by measuring the length of the fluid column after transfer to a calibrated, constant bore quartz capillary. Great care was taken to maintain $\mathrm{CO}_{2}$ equilibrated oil at both ends of the quartz capillary. The concentration of ${ }^{3} \mathrm{H}$-methoxy inulin in known volumes of tubular fluid samples, plasma, and urine was measured by scintillation counting using a LS7000 liquid scintillation counter (Beckman Instruments, Inc., Palo Alto, CA), as previously described from this laboratory (21). The $\mathrm{tCO}_{2}$ concentration in tubular fluid samples was measured by microcalorimetry (22). The volume of samples used for this determination was 14.0-19.0 nl. Details of the general methodology used to handle the tubular fluid samples were reported previously (21).

Plasma and urinary $\mathrm{tCO}_{2}$ were measured by a 960 carbon dioxide analyzer (Corning Medical and Scientific, Medfield, MA). Urine and arterial blood $\mathrm{pH}$ were measured with an Expandomatic Type IV pH meter (Beckman Instruments, Inc.). Plasma $\mathrm{PCO}_{2}$ was calculated from $\mathrm{tCO}_{2}$ and $\mathrm{pH}$ using $\mathrm{pK}_{\mathrm{a}}$ of 6.1 and $\alpha$ of 0.0301 . Plasma $\mathrm{Na}^{+}$and $\mathrm{K}^{+}$ concentrations were measured by flame photometry. Plasma solids were measured by refractometry. The latter values were identical in all experimental groups. Therefore, no correction for plasma water was made in the calculation of TF/P ratio of inulin and $\mathrm{tCO}_{2}$.

Calculations. Whole kidney GFR was calculated in the standard fashion. Single nephron glomerular filtration rate $(S N G F R)=T F / P_{I n}$ $\times$ tubular fluid flow rate, where $T F / P_{I n}$ is the tubular fluid to plasma inulin ratio. The SNGFR is expressed in $\mathrm{nl} \cdot \mathrm{min}^{-1}$. Fraction of filtered $\mathrm{tCO}_{2}$ delivered to end of proximal convolution or to final urine $=\mathrm{TF} /$ $\mathrm{P}$ or U/P tCO$/ / \mathrm{In} \times 100 \%$, where TF/P or U/P tCO $/ 2$ In is the tubular fluid or urine to plasma $\mathrm{tCO}_{2} /$ inulin ratio. The absolute reabsorption of $\mathrm{tCO}_{2}$ in the proximal convoluted tubule was calculated as the difference between the amount filtered and the amount delivered to the late proximal puncture site and is expressed in $\mathrm{pmol} \cdot \mathrm{min}^{-1}$.

Statistics. One-way analysis of variance was used to evaluate statistical differences among the experimental groups. The Duncan test was used to evaluate the level of significance between each two groups that were compared (23). This test was applied only when the null hypothesis of no difference between the four experimental groups was rejected. The paired $t$ test was used to compare clearance data between the control and experimental kidneys in the DNX animals (groups $C$ and D). The data are expressed as mean \pm SEM.

\section{Results}

A summary of the systemic and acid base data in the four groups is presented in Table I. A mild degree of respiratory acidosis $\left(\mathrm{PCO}_{2} 49.5\right.$ and $50.8 \mathrm{mmHg}$ ) was observed in groups $\mathrm{A}$ and $\mathrm{D}$, respectively. Increasing the tidal volume and/or rate of ventilation did not result in a further decrement in the arterial blood $\mathrm{PCO}_{2}$. Similar results were obtained previously in the dog (5) and are presumably due to the inhibitory effect of ACTZ on erythrocyte carbonic anhydrase. Ventilation with a $10 \% \mathrm{CO}_{2}$, $90 \% \mathrm{O}_{2}$ mixture during carbonic anhydrase inhibition (groups $B$ and $C$ ) resulted in a severe degree of hypercapnic acidosis of similar degree in both groups (Table I). Plasma $\mathrm{tCO}_{2}$ was significantly elevated in the latter groups compared with their control counterparts (groups A and D). Calculated plasma bicarbonate was also significantly higher in the hypercapnic groups compared with the normocapnic animals. This increment in plasma bicarbonate occurred despite the fact that a saline solution was infused in the hypercapnic animals and reflects the nonbicarbonate buffer capacity of the plasma and extracellular fluid (24). The four groups were not statistically different with respect to their body weights, final blood hematocrit values, and arterial blood pressures. The latter finding is of interest since in the dog, hypercapnia may result in a significant fall in systemic blood pressure (25). Finally, plasma sodium concentrations were not statistically different in groups $\mathrm{A}$ and $\mathrm{D}$ from those in $\mathrm{B}$ and $\mathrm{C}$ $(133.3 \pm 1.19 \mathrm{meq} / \mathrm{liter}$ and $132.4 \pm 0.94 \mathrm{meq} / \mathrm{liter}$, respectively, $P=$ NS). However, AHC (groups B and C) resulted in a significant increase in plasma potassium level $(4.65 \pm 0.09 \mathrm{meq} / \mathrm{liter}$ compared with $3.13 \pm 0.05 \mathrm{meq} / \mathrm{liter}$ in groups $\mathrm{A}$ and $\mathrm{D}(P$ $<0.001$ ).

The clearance data from groups A and B are listed on Table II. AHC resulted in a prompt and significant reduction in urinary flow rate. Total GFR was not statistically different between the two groups. Urinary to plasma $\mathrm{tCO}_{2}$ ratio was significantly decreased in the hypercapnic animals (ACTZ, 9.05 \pm 0.16 ; ACTZ plus high $\left.\mathrm{PCO}_{2}, 6.42 \pm 0.12, P<0.001\right)$. The fractional excretion

Table I. Systemic and Acid-base Data

\begin{tabular}{|c|c|c|c|c|c|c|c|}
\hline Group & $\mathrm{PCO}_{2}$ & $\mathrm{pH}$ & Plasma $\mathrm{tCO}_{2}$ & Plasma $\mathrm{HCO}_{3}^{-}$ & MBP & Body weight & Hct \\
\hline & $m m H g$ & & $m M / l i t e r$ & $m M / l i t e r$ & $m m H g$ & $g$ & $\%$ \\
\hline \multirow[t]{2}{*}{ A. $\operatorname{ACTZ}^{*}(n=7)$} & 49.5 & 7.34 & 27.6 & 26.1 & 118 & 329 & 48.0 \\
\hline & 1.1 & 0.01 & 0.5 & 0.5 & 5 & 7 & 0.8 \\
\hline \multirow[t]{2}{*}{ B. $\mathrm{ACTZ}+\mathrm{AHC}(n=7)$} & 120.1 & 7.02 & 33.8 & 30.2 & 125 & 334 & 48.9 \\
\hline & 0.8 & 0.004 & 0.3 & 0.3 & 2 & 7 & 0.5 \\
\hline \multirow[t]{2}{*}{ C. $\mathrm{ACTZ}+\mathrm{AHC}+\mathrm{DNX}(n=6)$} & 119.6 & 7.00 & 32.0 & 28.4 & 122 & 327 & 47.0 \\
\hline & 1.8 & 0.006 & 0.4 & 0.4 & 3 & 4 & 0.7 \\
\hline \multirow[t]{2}{*}{ D. $\mathrm{ACTZ}+\mathrm{DNX}(n=5)$} & 50.8 & 7.33 & 27.2 & 25.7 & 110 & 335 & 47.8 \\
\hline & 3.4 & 0.02 & 0.6 & 0.6 & 3 & 6 & 0.9 \\
\hline B vs. A & $P<0.01$ & $<0.01$ & $<0.01$ & $<0.001$ & NS & NS & NS \\
\hline C vs. B & $P$ NS & NS & $<0.05$ & $<0.01$ & NS & NS & NS \\
\hline C vs. A & $P<0.01$ & $<0.01$ & $<0.01$ & $<0.01$ & NS & NS & NS \\
\hline D vs. C & $P<0.01$ & $<0.01$ & $<0.01$ & $<0.01$ & NS & NS & NS \\
\hline D vs.A & $P$ NS & NS & NS & NS & NS & NS & NS \\
\hline
\end{tabular}

MBP, mean arterial blood pressure; $n$, number of rats. Results on this and subsequent tables are expressed as the mean \pm SEM. 
Table II. Urinary Excretion Data

\begin{tabular}{|c|c|c|c|c|c|}
\hline Group & $\mathbf{v}$ & GFR & $\mathrm{U} / \mathrm{P} \mathrm{tCO}_{2}$ & Urine $\mathrm{pH}$ & $\mathrm{FE} \mathrm{tCO}_{2}$ \\
\hline & $\mu l \cdot \min ^{-l}$ & $\begin{array}{l}\mathrm{ml} \cdot \min ^{-1} \cdot 100 \mathrm{~g} \\
\text { body weight }\end{array}$ & & & $\%$ \\
\hline A. ACTZ & 74.9 & 0.53 & 9.1 & 7.84 & 39.04 \\
\hline$(n=7)$ & 4.1 & 0.02 & 0.2 & 0.01 & 1.48 \\
\hline B. $A C T Z$ & 51.6 & 0.48 & 6.4 & 7.57 & 20.23 \\
\hline $\begin{array}{l}+\mathrm{AHC} \\
(n=7)\end{array}$ & 3.7 & 0.01 & 0.1 & 0.02 & 0.76 \\
\hline A vs. B & $P<0.005$ & NS & $<0.001$ & $<0.001$ & $<0.001$ \\
\hline
\end{tabular}

V, urine flow rate; GFR represents results from both kidneys.

(FE) of $\mathrm{tCO}_{2}$ was $39.04 \pm 1.48 \%$ in the normocapnic animals treated with ACTZ. This value is in general agreement with other published data regarding the effects of inhibition of renal carbonic anhydrase activity in the rat $(26,27)$, and demonstrates that $\sim 60 \%$ of the filtered load of $\mathrm{tCO}_{2}$ was reabsorbed. AHC resulted in a substantial reduction in fractional excretion (FE) $\mathrm{tCO}_{2}$ to $20.23 \pm 0.76 \%, P<0.001$ (vs. group $\mathrm{A}$ ), indicating that $\mathrm{tCO}_{2}$ reabsorption in the presence of $\mathrm{ACTZ}$ was sensitive to changes in arterial blood $\mathrm{CO}_{2}$ tension.

The micropuncture data from the superficial proximal convoluted tubule are presented in Table III. During administration of $A C T Z$, group $A$, the late proximal $T F / P_{\text {In }}$ was $1.43 \pm 0.03$ and the SNGFR $43.8 \pm 1.7 \mathrm{nl} / \mathrm{min}$. The late proximal $\mathrm{TF} / \mathrm{P} \mathrm{tCO}_{2}$ ratio was $1.19 \pm 0.08$. Inhibition of renal carbonic anhydrase resulted in fractional delivery of $\mathrm{tCO}_{2}$ of $85 \pm 6 \%$ to the end of proximal convoluted tubule, demonstrating that only $15 \%$ of filtered load of $\mathrm{tCO}_{2}$ was reabsorbed in the proximal convoluted tubule under these circumstances. These data are similar to those obtained by others $(15,28)$ in plasma repleted rats.
Induction of AHC during carbonic anhydrase inhibition (group B) was associated with two major findings. First, under these conditions, the SNGFR was significantly decreased to $32.6 \pm 0.7 \mathrm{nl} \cdot \mathrm{min}^{-1}, P<0.01$, and the $\mathrm{TF} / \mathrm{P}_{\mathrm{In}}$ was elevated to $1.70 \pm 0.08, P<0.01$, both compared with group A. Second, fractional $\mathrm{tCO}_{2}$ reabsorption in the proximal tubule was markedly enhanced by AHC; i.e., fractional delivery of $\mathrm{tCO}_{2}$ to the end of the proximal tubule was $62 \pm 4 \%, P<0.01$, compared with group $\mathrm{A}$. The decrement in whole kidney $\mathrm{tCO}_{2}$ excretion after AHC is therefore reflected by a corresponding change in fractional $\mathrm{tCO}_{2}$ reabsorption in the superficial proximal tubule. The fact that the difference in the TF/ $\mathrm{P} \mathrm{tCO}_{2}$ ratio between groups $A$ and $B$ did not reach statistical significance may be related to the simultaneous increment in proximal fluid reabsorption in group B after AHC.

The single nephron filtered load of $\mathrm{tCO}_{2}$ in groups $\mathrm{A}$ and $\mathrm{B}$ were comparable (Table III). The absolute reabsorption of $\mathrm{tCO}_{2}$ in group $\mathrm{B}, 410 \pm 47 \mathrm{pmol} \cdot \mathrm{min}^{-1}$, was significantly greater than that observed in group $\mathrm{A}, 170 \pm 74 \mathrm{pmol} \cdot \mathrm{min}^{-1}, P<0.05$. To evaluate the contribution of renal sympathetic nerve activity to the renal response to hypercapnia, additional studies, groups $C$ and $D$, were performed in which the left kidney was DNX before the study. Induction of AHC after denervation (group C) resulted in arterial blood $\mathrm{pH}$ and $\mathrm{PCO}_{2}$ values similar to that noted in group B, Table I. There was a mild decrease in plasma $\mathrm{tCO}_{2}$ as well as in the calculated plasma bicarbonate concentration in group C compared with group $B$.

Clearance data comparing the left DNX kidney with the right, untouched kidney in group $\mathrm{C}$ are presented in Table IV. Single kidney GFR was mildly elevated in the DNX kidney $(0.28 \pm 0.01 \mathrm{ml} / \mathrm{min}$ compared with the innervated kidney, $0.24 \pm 0.01 \mathrm{ml} / \mathrm{min}, P<0.01$ ). This result is of interest in view of the finding that there was no significant difference in total kidney GFR between groups $A$ and $B$. The reason for this discrepancy is unclear, but it may be that a change in whole kidney GFR, resulting from sympathetic overactivity after AHC, is rel-

Table III. Micropuncture Data

\begin{tabular}{|c|c|c|c|c|c|c|c|}
\hline Group & $\mathbf{T F} / \mathbf{P}_{\mathbf{l a}}$ & SNGFR & $\mathrm{FLtCO}_{2}$ & $\mathrm{TFtCO}_{2}$ & $\begin{array}{l}\mathrm{TF} / \mathrm{P} \\
\mathrm{tCO}_{2}\end{array}$ & $\mathrm{ARtCO}_{2}$ & $\mathrm{FDtCO}_{2}$ \\
\hline & & $n l \cdot \min ^{-1}$ & $\mathrm{pmol} \cdot \mathrm{min}^{-1}$ & $m M / l i t e r$ & & $\mathrm{pmol} \cdot \mathrm{min}^{-1}$ & $\%$ \\
\hline \multirow[t]{2}{*}{ A. $\operatorname{ACTZ}(n=7)$} & 1.43 & 43.8 & 1,189 & 33.3 & 1.19 & 170 & 85 \\
\hline & 0.03 & 1.7 & 43 & 2.8 & 0.08 & 74 & 6 \\
\hline \multirow[t]{2}{*}{ B. $\mathrm{ACTZ}+\mathrm{AHC}(n=7)$} & 1.70 & 32.6 & 1,085 & 35.3 & 1.05 & 410 & 62 \\
\hline & 0.08 & 0.7 & 28 & 2.1 & 0.06 & 47 & 4 \\
\hline \multirow[t]{2}{*}{ C. $\mathrm{ACTZ}+\mathrm{AHC}+\mathrm{DNX}(n=6)$} & 1.47 & 47.7 & 1,527 & 26.22 & 0.83 & 653 & 58 \\
\hline & 0.06 & 2.0 & 71 & 1.6 & 0.05 & 102 & 5 \\
\hline \multirow[t]{2}{*}{ D. $\mathrm{ACTZ}+\mathrm{DNX}(n=5)$} & 1.38 & 44.7 & 1,210 & 29.7 & 1.08 & 262 & 78 \\
\hline & 0.05 & 2.8 & 109 & 1.7 & 0.05 & 45 & 3 \\
\hline B vs. $\mathrm{A}$ & $P<0.01$ & $<0.01$ & NS & NS & NS & $<0.05$ & $<0.01$ \\
\hline C vs. B & $P<0.01$ & $<0.01$ & $<0.01$ & $<0.05$ & $<0.05$ & $<0.05$ & NS \\
\hline C vs. A & $P$ NS & NS & $<0.01$ & $<0.05$ & $<0.05$ & $<0.01$ & $<0.01$ \\
\hline D vs. C & $P$ NS & NS & $<0.01$ & NS & $<0.05$ & $<0.01$ & $<0.05$ \\
\hline D vs. A & $P$ NS & NS & NS & NS & NS & NS & NS \\
\hline
\end{tabular}

FLtCO 2 , single nephron filtered load of $\mathrm{tCO}_{2} ; \mathrm{TFtCO}_{2}$, tubular fluid $\left[\mathrm{tCO}_{2}\right] ; \mathrm{ARtCO}_{2}$, absolute reabsorption rate of $\mathrm{tCO}_{2} ; \mathrm{FDtCO}_{2}$, fractional delivery of $\mathrm{tCO}_{2}$ to end of proximal tubule. 
Table IV. Comparison of Clearance Data from the Innervated and DNX Kidneys in Group C

\begin{tabular}{llll}
\hline & Innervated & DNX & \\
\hline & & & $P$ \\
GFR $\left(\mathrm{ml} \cdot \mathrm{min}^{-1} \cdot 100 \mathrm{~g}\right.$ body & & & \\
$\quad$ weight & & & \\
FE tCO & & & \\
& $0.24 \pm 0.01$ & $0.28 \pm 0.01$ & $<0.01$ \\
& $18.0 \pm 1.3$ & $22.7 \pm 0.7$ & $<0.02$
\end{tabular}

atively small and can be depicted only when the DNX kidney is compared with the untouched kidney in the same hypercapnic animal. There was a slight but significant difference in $\mathrm{FEtCO}_{2}$

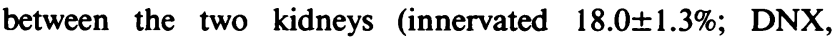
$22.7 \pm 0.7 \%, P<0.02$ ). Both values are similar to the value observed in group $\mathrm{B}$. The fractional excretion of $\mathrm{tCO}_{2}$ in the DNX kidney of group D, ACTZ alone, was $35.8 \pm 2.9 \%$, which was significantly greater than the $22.7 \pm 0.7 \%$ noted in the DNX kidney in group $\mathrm{C}$. Thus, renal sympathetic activity was not responsible for the enhanced renal $\mathrm{tCO}_{2}$ reabsorption induced by the AHC.

Table III also lists the values obtained from micropuncture results from groups $C$ and $D$, in which the left (experimental) kidney was DNX before study. DNX of the experimental kidney did not affect the response to ACTZ noted in the proximal tubule, group D vs. group A. The observation that DNX did not affect proximal tubular function in the absence of AHC (group D vs. group A) is of interest. These findings suggest that renal DNX may not affect the SNGFR and proximal tubular fluid reabsorption if baseline sympathetic nerve activity is not increased.

Renal DNX prevented a reduction in SNGFR and an increase in proximal $T F / P_{\text {In }}$ ratio from occurring in response to AHC, group B vs. group C. Despite the DNX, an increase in proximal $\mathrm{tCO}_{2}$ reabsorption was still observed in response to AHC, group $\mathrm{C}$ vs. group $\mathrm{D}$. The TF/ $\mathrm{P} \mathrm{tCO}_{2}$ ratio in group $\mathrm{C}$, $0.83 \pm 0.05$, was less than noted in group $\mathrm{D}, 1.08 \pm 0.05, P<0.05$. Fractional delivery of $\mathrm{tCO}_{2}$ to the late proximal tubule after AHC, group C, was $20 \%$ less than in group D, which was approximately the same difference as was noted between groups $\mathrm{A}$ and $\mathrm{B}$, the groups in which renal innervation was intact. The absolute proximal reabsorption of $\mathrm{tCO}_{2}$ was significantly greater after AHC, group C, $653 \pm 102 \mathrm{pmol} \cdot \mathrm{min}^{-1}$, than in the denervated control, group $D, 262 \pm 45, P<0.01$. The single nephron filtered load of $\mathrm{tCO}_{2}$ was significantly greater in group $\mathrm{C}$ than in group D, Table III. However, after correcting the plasma $\mathrm{tCO}_{2}$ concentration for the arterial $\mathrm{PCO}_{2}$ in the two groups, the filtered load of bicarbonate was not different in the two groups, $1,352 \pm 52$, group $C$, vs. $1,150 \pm 88 \mathrm{pmol} \cdot \mathrm{min}^{-1}$, group $\mathrm{D}$, $P=$ NS.

The measurement of $\mathrm{tCO}_{2}$ in tubular fluid by microcalorimetry reflects not only measurement of bicarbonate in the sample, but that of dissolved $\mathrm{CO}_{2}$ as well. Without precise knowledge of the renal cortical $\mathrm{PCO}_{2}$, it is not possible to correct the measured tubular fluid $\mathrm{tCO}_{2}$ for the latter value. In view of the difference between the systemic and renal cortical $\mathrm{PCO}_{2}$ and an amplification of this difference during respiratory acidosis (28), correction of the tubular fluid $\mathrm{tCO}_{2}$ concentration for the renal cortical $\mathrm{PCO}_{2}$ will result in a greater change than correction of plasma $\mathrm{tCO}_{2}$ for arterial blood $\mathrm{PCO}_{2}$. Consequently, proximal TF/P bicarbonate ratios would be lower than the TF/P $\mathrm{tCO}_{2}$ ratios shown with proportionately greater reductions in this ratio in $\mathrm{AHC}$ rats because of the difference in renal cortical $\mathrm{PCO}_{2}$ as mentioned above. Given these considerations, it is clear that the rates of fractional and absolute $\mathrm{tCO}_{2}$ reabsorption demonstrated above reflect corresponding changes in the reabsorptive rate of bicarbonate.

It is unlikely that the increase in single nephron filtered load of $\mathrm{tCO}_{2}$ in group $\mathrm{C}$, in contrast to group $\mathrm{D}$, contributes significantly to the difference in absolute proximal absorption noted between the two groups. Variations in the filtered load of $\mathrm{tCO}_{2}$ do not, of themselves, alter fractional proximal $\mathrm{tCO}_{2}$ reabsorption in the ACTZ-treated rat (15). Accordingly, $<20 \%$ of the difference in absolute $\mathrm{tCO}_{2}$ reabsorption, in group $\mathrm{C}$ in comparison with group $\mathrm{D}$, can be attributed to the higher filtered load present in the former group. Further, the differences in proximal $\mathrm{tCO}_{2}$ reabsorption cannot be attributed to differences in tubular fluid flow rate (15) as they were identical in these two groups.

Intratubular $\mathrm{pH}$ measurements were performed in six late proximal convolutions of three normocapnic, ACTZ-treated, DNX animals, and in six tubules of three hypercapnic, DNX animals treated with ACTZ, Table V. Mean plasma pH and $\mathrm{tCO}_{2}$ in the normocapnic group were $7.35 \pm 0.01$ and $25.7 \pm 0.33$ $\mathrm{mM}$, respectively; they were $7.05 \pm 0.01$ and $31.7 \pm 0.88 \mathrm{mM}$, respectively, in the hypercapnic group. These values are not statistically different from those obtained in experimental groups $\mathrm{C}$ and $\mathrm{D}$, the groups that were handled identically to those in which the $\mathrm{pH}$ measurements were made. It is assumed, therefore, that the in situ $\mathrm{pH}$ measurements obtained in these animals accurately reflect the in situ $\mathrm{pH}$ in groups $\mathrm{C}$ and $\mathrm{D}$ in which determination of $\mathrm{tCO}_{2}$ transport was made. The in situ late proximal intratubular $\mathrm{pH}$ was $6.90 \pm 0.01$ in the animals treated with ACTZ only. This value is significantly different $(P<0.005)$ from the value of $6.58 \pm 0.02$ obtained in the proximal segment of the animals treated with ACTZ and subjected to AHC.

\section{Discussion}

The findings of the present study confirm earlier observations (5-7) which demonstrate that renal bicarbonate reabsorption in the presence of an inhibitor of carbonic anhydrase may be significantly increased by elevation of the arterial $\mathrm{PCO}_{2}$. An increase of $\sim 20 \%$ in fractional $\mathrm{tCO}_{2}$ reabsorption was noted after AHC in the present studies, indicating that carbonic anhydrase independent bicarbonate reabsorption was quite sensitive to changes in arterial $\mathrm{PCO}_{2}$. Our data also demonstrate that the effect of $\mathrm{AHC}$, in this experimental setting, is reflected by a cor-

Table V. Late Proximal Luminal pH Measurements

\begin{tabular}{|c|c|c|c|}
\hline & $\mathrm{ACTZ}+\mathrm{AHC}$ & & ACTZ \\
\hline \multirow[t]{2}{*}{ Rat 1} & $6.62^{*}$ & & 6.84 \\
\hline & 6.55 & & 6.84 \\
\hline \multirow[t]{2}{*}{ Rat 2} & 6.51 & & 6.95 \\
\hline & 6.57 & & 6.94 \\
\hline \multirow[t]{2}{*}{ Rat 3} & 6.61 & & 6.92 \\
\hline & 6.65 & & 6.91 \\
\hline Mean & $6.58 \pm 0.02$ & $P<0.005$ & $6.90 \pm 0.01$ \\
\hline
\end{tabular}

\footnotetext{
* Each measurement was obtained from a separate tubule.
} 
responding change in $\mathrm{tCO}_{2}$ reabsorption in the proximal convoluted tubule. This observation, however, does not exclude an effect of AHC in other nephron segments or nephron groups under these circumstances. Such a major impact of AHC on proximal bicarbonate reabsorption is of interest in view of the finding that in the normal rat, when renal carbonic anhydrase activity is intact, AHC induces only a mild effect on proximal bicarbonate reabsorption, or has no effect at all (29-32). Finally, our data show that AHC can have a marked influence on the SNGFR and fluid reabsorption of the superficial proximal tubule. These alterations appear to be mediated by renal sympathetic nerve stimulation, secondary to the AHC. However, the increase in $\mathrm{tCO}_{2}$ reabsorption in the superficial proximal tubule after AHC was unrelated to indirect or direct effects of the increase in sympathetic activity, as renal denervation prevented $\mathrm{AHC}$ from affecting either the SNGFR and proximal fluid reabsorption; yet proximal $\mathrm{tCO}_{2}$ reabsorption remained substantially elevated.

The increase in $\mathrm{tCO}_{2}$ reabsorption in the innervated group B, in comparison with group A, may be attributable to several factors, and not only the result of the direct effect of an acute increase in $\mathrm{PCO}_{2}$ on proximal $\mathrm{H}^{+}$transport. Cogan et al. (15) have suggested that proximal tubular $\mathrm{tCO}_{2}$ reabsorption in the ACTZ-treated rat may vary directly with the peritubular capillary protein concentration. If AHC in the innervated group B increased the filtration fraction in superficial nephrons as a consequence of enhanced renal sympathetic nerve activity (14), such an increase could contribute to the increase in the $\mathrm{tCO}_{2}$ reabsorption in this group. Second, renal sympathetic activity, of itself, can directly stimulate proximal $\mathrm{tCO}_{2}$ reabsorption and could contribute to the increase noted in group $B(16,17)$.

In contrast to the findings in group $\mathrm{B}$, the contribution of these indirect and direct effects of renal sympathetic activity would not be responsible for the increase in $\mathrm{tCO}_{2}$ reabsorption noted after AHC in the DNX state. Denervation prevented a reduction in SNGFR after AHC, and we presume, based upon other studies (14), that no change in renal plasma flow occurred in these rats. Similarly, any direct effect of sympathetic nerve activity on $\mathrm{tCO}_{2}$ reabsorption would be removed by the denervation. The results in the DNX studies, therefore, indicate that the effects of $\mathrm{AHC}$ on proximal $\mathrm{tCO}_{2}$ reabsorption are not only mediated via stimulation of renal sympathetic activity.

After the administration of an inhibitor of renal carbonic anhydrase, fractional $\mathrm{tCO}_{2}$ delivery to the end of the superficial proximal tubule remains remarkably constant when examined in the normal or plasma expanded rat or after the induction of metabolic acidosis or metabolic alkalosis $(15,33)$. Thus, as a consequence of the considerable variability of the filtered load of $\mathrm{tCO}_{2}$ or some derivative thereof, noted in these diverse experimental settings, the constancy of fractional $\mathrm{tCO}_{2}$ reabsorption is associated with large differences in absolute reabsorption. In contrast to the observations cited above, the present experiments indicate that $\mathrm{AHC}$ increases $\mathrm{tCO}_{2}$ reabsorption in the proximal tubule of the ACTZ-treated rat independent of an increase in the filtered load.

Net bicarbonate transport in the proximal convoluted tubule is felt to be a function of the secretion of $\mathrm{H}^{+}$coupled with a small passive backleak of bicarbonate (34). In this segment, $\mathrm{H}^{+}$ secretion is primarily a result of a $\mathrm{Na}^{+} / \mathrm{H}^{+}$antiporter located in the luminal membrane (35). In the absence of an inhibitor of carbonic anhydrase, this segment demonstrates a remarkable capacity to reabsorb bicarbonate, particularly if the tubular flow rate and the luminal bicarbonate concentration are optimal (36, 37). ACTZ treatment is felt to reduce proximal bicarbonate reabsorption by reducing the cellular supply of $\mathrm{H}^{+}$available for secretion, and, at least in part, by allowing luminal $\mathrm{H}_{2} \mathrm{CO}_{3}$ to accumulate, thereby inducing a pH gradient between cell and lumen unfavorable for proton secretion. The continued reabsorption of bicarbonate in the proximal tubule after ACTZ has been ascribed to several mechanisms $(8,38)$. Some of this bicarbonate can be attributed to the $\mathrm{H}^{+}$supplied by the uncatalyzed hydration and hydroxylation of $\mathrm{CO}_{2}$ reactions, but the numbers so supplied are insufficient to account for the quantity of bicarbonate reabsorbed (27). Cogan et al. (27) have recently estimated the contribution of the uncatalyzed reactions to proximal bicarbonate reabsorption, taking into consideration the effects of alterations in intracellular bicarbonate concentration. Their estimates would predict that the uncatalyzed rate of $\mathrm{H}^{+}$secretion is insufficient to account for the rate of carbonic anhydrase independent reabsorption observed unless the intracellular $\mathrm{pH}$ were in excess of 8.5. Although it has been shown that the intracellular pH becomes more alkaline during carbonic anhydrase inhibition $(39,40)$, an intracellular $\mathrm{pH}$ of this magnitude, together with an intratubular acid disequilibrium $\mathrm{pH}$, would result in a $\mathrm{pH}$ gradient across the apical membrane of $\sim 2 \mathrm{pH}$ units. The authors considered a $\mathrm{H}^{+}$gradient of this magnitude to be unlikely.

To determine if an increase in cell $\mathrm{PCO}_{2}$ as a consequence of the AHC contributed significantly to the increase in proximal bicarbonate reabsorption noted in group $\mathrm{C}$, in comparison to group D, we have extended the calculations of Cogan et al. (27) using slightly different kinetic constants (41). By computer modeling (see Appendix), we were able to estimate the rate of cellular $\mathrm{H}^{+}$production by the uncatalyzed reactions as a function of both intracellular $\mathrm{pH}$ and $\mathrm{PCO}_{2}$ ranging from 40 to $180 \mathrm{mmHg}$, at a constant intracellular bicarbonate concentration of $25 \mathrm{mM}$. The absolute rate of $\mathrm{tCO}_{2}$ reabsorption observed after $\mathrm{AHC}$ in group $\mathrm{C}$ is substantially higher than that predicted by the uncatalyzed reactions, even when the cortical $\mathrm{PCO}_{2}$ is $\sim 60 \mathrm{mmHg}$ higher than the arterial $\mathrm{PCO}_{2}$. Thus, unless one assumes an extremely alkaline intracellular $\mathrm{pH}\left(\mathrm{pH}\right.$ of 9.0 at a cortical $\mathrm{PCO}_{2}$ of 120 or $180 \mathrm{mmHg}$ ), the anticipated rate of the uncatalyzed reactions cannot account for the magnitude of the proximal bicarbonate reabsorption observed after AHC.

A number of years ago, Rector (8) proposed another mechanism that would account for a continuous supply of $\mathrm{H}^{+}$to a proton secretory process in the presence of carbonic anhydrase inhibition (8). He suggested that the $\mathrm{H}_{2} \mathrm{CO}_{3}$, which accumulated in the lumen after ACTZ, might cycle from the lumen into the cell, where it would dissociate. Thus, $\mathrm{H}^{+}$would be available for secretion not dependent upon continuous production from the uncatalyzed hydration and hydroxylation of $\mathrm{CO}_{2}$. Cogan (9) has recently argued that the direct relationship between luminal bicarbonate concentration and bicarbonate reabsorption in the presence of $\mathrm{ACTZ}$ is the result of a proximal $\mathrm{H}^{+}$secretory mechanism that is limited by the lumen to cell $\mathrm{pH}$ gradient. In his view, $\mathrm{H}^{+}$secretion will vary directly with the luminal bicarbonate concentration and, at a constant luminal $\mathrm{pH}$, the luminal $\mathrm{H}_{2} \mathrm{CO}_{3}$ concentration will parallel the luminal bicarbonate concentration. The proportional change in $\mathrm{H}_{2} \mathrm{CO}_{3}$ concentration with luminal bicarbonate concentration will allow more $\mathrm{H}_{2} \mathrm{CO}_{3}$ to enter the cell at high luminal bicarbonate concentrations, thus accounting for more bicarbonate to be reabsorbed than when the luminal bicarbonate concentration is lowered.

The increase in proximal $\mathrm{tCO}_{2}$ reabsorption in the present 
studies cannot be attributed precisely to the same mechanism. Based upon approximations of the renal cortical $\mathrm{PCO}_{2}$ (below), luminal bicarbonate concentrations in the AHC groups would be approximately equal to (group B) or below (group C) their appropriate controls, groups $A$ and $D$, respectively. Further, in contrast to the hypothesis put forward by Cogan (9) to explain parallel changes in luminal $\mathrm{H}_{2} \mathrm{CO}_{3}$ and bicarbonate concentrations at a constant luminal $\mathrm{pH}$, our data indicate that, at least under our experimental circumstances, the luminal $\mathrm{pH}$ is not fixed. Yet, our data are compatible with luminal $\mathrm{H}_{2} \mathrm{CO}_{3}$ as a source for $\mathrm{H}^{+}$for secretion and with an increase in luminal $\mathrm{H}_{2} \mathrm{CO}_{3}$ after AHC. The luminal pH in the rats treated as in group D was 6.90. Assuming a cortical $\mathrm{PCO}_{2}$ of $60 \mathrm{mmHg}$ (33), and using a luminal bicarbonate concentration of $27.9 \mathrm{mM}$ and a $\mathrm{pK}_{\mathrm{a}}$ of 3.57 , the calculated luminal $\mathrm{H}_{2} \mathrm{CO}_{3}$ concentration at this $\mathrm{pH}$ was $13 \mu \mathrm{M}$. No experimental data are available to indicate the cortical $\mathrm{PCO}_{2}$ in the hypercapnic animals in group $\mathrm{C}$, but it likely can be expected to exceed $150 \mathrm{mmHg}$ (33). If we assume a cortical $\mathrm{PCO}_{2}$ of $180 \mathrm{mmHg}$, a luminal $\mathrm{H}_{2} \mathrm{CO}_{3}$ concentration of $20 \mu \mathrm{M}$ can be calculated from the luminal $\mathrm{pH}$ (6.58) and corrected luminal bicarbonate concentration. ${ }^{2}$ The permeability of the apical membrane of the proximal convoluted tubule to $\mathrm{H}_{2} \mathrm{CO}_{3}$ and the $\mathrm{H}_{2} \mathrm{CO}_{3}$ concentration gradient across this membrane are unknown. Nevertheless, the higher luminal $\mathrm{H}_{2} \mathrm{CO}_{3}$ in the $\mathrm{AHC}$ rats is consistent with a greater potential source for $\mathrm{H}^{+}$production derived from $\mathrm{H}_{2} \mathrm{CO}_{3}$, which moves from lumen to cell. Our studies, unfortunately, do not permit a precise determination of the amount of $\mathrm{H}_{2} \mathrm{CO}_{3}$ that has traversed the luminal membranes into the cell and contributed to $\mathrm{H}^{+}$secretion. Theoretically, this could be all of the $\mathrm{H}_{2} \mathrm{CO}_{3}$ produced by $\mathrm{H}^{+}$secretion that did not noncatalytically break down in the lumen. Luminal pH measurements and calculated $\mathrm{H}_{2} \mathrm{CO}_{3}$ concentrations are not reported for rats studied as groups $\mathrm{A}$ and B. The direct and indirect consequences of renal sympathetic stimulation after AHC (group B) prevents examination of the singular effects of the increase in $\mathrm{PCO}_{2}$ per se on $\mathrm{tCO}_{2}$ reabsorption, and likely these parameters as well.

If we assume that $\mathrm{H}_{2} \mathrm{CO}_{3}$ cycling may provide a continuous source of $\mathrm{H}^{+}$for secretion in the ACTZ-treated state, the ability of $\mathrm{AHC}$ to increase $\mathrm{H}^{+}$secretion relative to the control state requires explanation. The increase in proximal $\mathrm{tCO}_{2}$ reabsorption after AHC presumably reflects stimulation of the $\mathrm{Na}^{+} / \mathrm{H}^{+}$antiporter in the luminal membrane, or an altered luminal membrane permeability to $\mathrm{H}^{+}$. The activity of this antiporter is dictated, in part, by the $\mathrm{pH}$ gradient across the luminal membrane. In addition, Aronson et al. (42) have demonstrated in brush border membrane vesicles that a reduction in intravesicular $\mathrm{pH}$ stimulates the activity of the $\mathrm{Na}^{+} / \mathrm{H}^{+}$antiporter in a manner that suggests allosteric interaction of $\mathrm{H}^{+}$with an activator or modifier site. Consequently, a parallel increase in the intracellular and intratubular concentrations of $\mathrm{H}^{+}$may potentially enhance $\mathrm{Na}^{+} / \mathrm{H}^{+}$exchange without a measurable change in $\mathrm{pH}$ gradient across the luminal membrane. On the other hand, if AHC were to disproportionately increase intracellular $\mathrm{H}^{+}$concentration in the proximal tubule of the ACTZ-treated rat relative to the intratubular $\mathrm{H}^{+}$concentration, a more favorable $\mathrm{pH}$ gradient would be established across the luminal membrane and an increase in antiporter activity and $\mathrm{tCO}_{2}$ reabsorption might be

2. The $\mathrm{H}_{2} \mathrm{CO}_{3}$ concentrations were calculated from late proximal values. Whether the same concentrations would exist along the entire length of the proximal tubule will require additional study. anticipated. If a more favorable pH gradient were generated between cell and lumen by AHC, this may not be reflected by blood to lumen $\mathrm{pH}$ gradients. The $\mathrm{pH}$ gradients between blood and lumen were virtually identical in groups $C$ and $D$.

In summary, the present studies indicate that AHC can dramatically increase renal $\mathrm{tCO}_{2}$ reabsorption in the absence of renal carbonic anhydrase activity. An increase in $\mathrm{tCO}_{2}$ reabsorption under these circumstances can be shown to occur in the proximal convoluted tubule. It is suggested that $\mathrm{H}_{2} \mathrm{CO}_{3}$, cycling from luminal to cell, provides a continuous source of $\mathrm{H}^{+}$ for secretion.

\section{Appendix}

The source of intracellular proton generation during carbonic anhydrase inhibition is the uncatalyzed reaction which consists of the following: (1) $\mathrm{CO}_{2}$ hydration: $\mathrm{CO}_{2}+\mathrm{H}_{2} \mathrm{O} \underset{k_{-1}}{\stackrel{k_{1}}{\rightleftharpoons}} \mathrm{H}_{2} \mathrm{CO}_{3} \leftrightarrow \mathrm{H}^{+}+\mathrm{HCO}_{3}$; and (2) $\mathrm{CO}_{2}$ hydroxylation: $\mathrm{H}_{2} \mathrm{O} \rightleftharpoons \mathrm{OH}^{-}+\mathrm{H}^{+} \quad \mathrm{CO}_{2}+\mathrm{OH}^{-} \underset{k_{-2}}{\stackrel{k_{2}}{\rightleftharpoons}} \mathrm{HCO}_{3}$.

The latter reaction, which makes a significant contribution to the disappearance of $\mathrm{CO}_{2}$ in aqueous solutions at $\mathrm{pH}>7.8(41)$ is an additional source of intracellular $\mathrm{H}^{+}$supply; at $\mathrm{pH}>10$, it dominates the uncatalyzed reaction. The relative contribution of the hydration and hydroxylation of $\mathrm{CO}_{2}$ will be, therefore, $\mathrm{pH}$ dependent. The maximal rate of $\mathrm{H}^{+}$ion supply by the uncatalyzed reaction in the proximal nephron is:

$\left(\mathrm{dH}^{+}\right) /(\mathrm{dt})=\left(\left[\mathrm{CO}_{2}\right] k_{1}-\left[\mathrm{H}_{2} \mathrm{CO}_{3}\right] k_{-1}\right.$

$$
+\left[\mathrm{OH}^{-}\right]\left[\mathrm{CO}_{2}\right] k_{2}-\left[\mathrm{HCO}_{3}^{-}\right] k_{-2} \times \mathrm{V}_{\mathrm{c}},
$$

where $\mathrm{V}_{\mathrm{c}}=$ the volume of proximal tubule cells and $\left[\mathrm{CO}_{2}\right],\left[\mathrm{H}_{2} \mathrm{CO}_{3}\right]$, $\left[\mathrm{OH}^{-}\right]$, and $\left[\mathrm{HCO}_{3}^{-}\right]$refer to the intracellular concentrations of these species.

Cogan et al. (27) have shown that the rate of the uncatalyzed $\mathrm{H}^{+}$ion supply $\left(\mathrm{dH}^{+}\right) /(\mathrm{dt})$ depends mainly on intracellular $\mathrm{pH}$ and bicarbonate concentration. Their calculation is based on the assumption that the intracellular carbonic acid concentration is in equilibrium with intracellular $\left[\mathrm{H}^{+}\right]_{\mathrm{i}}$ and bicarbonate $\left[\mathrm{HCO}_{3}\right]_{\mathrm{i}}$. Thus: $\left[\mathrm{H}_{2} \mathrm{CO}_{3}\right]_{\mathrm{i}}=\left(\left[\mathrm{H}^{+}\right]_{\mathrm{i}}\right.$ $\left.\times\left[\mathrm{HCO}_{3}^{-}\right]_{\mathrm{i}}\right) /\left(2.7 \times 10^{-4} \mathrm{M}\right)$. Furthermore, the intracellular $\mathrm{PCO}_{2}$ is constant and is similar to the cortical $\mathrm{PCO}_{2}$ occurring during hypercapnia. To determine the influence of variations in $\mathrm{PCO}_{2}$ on the $\mathrm{H}^{+}$generation by the uncatalyzed reaction, we extended their calculations to include cortical $\mathrm{PCO}_{2}$ as an additional variable. Using a computer model we were able to predict the effect of alterations in cortical $\mathrm{PCO}_{2}$ ranging from 40 to $180 \mathrm{mmHg}$ on $\mathrm{H}^{+}$ion supply independent of changes in intracellular pH and bicarbonate concentration. The model uses the same tubular geometry data and kinetics as used by Cogan et al. (27), with the exception that $k_{1}$ and $k_{-1}$ were replaced as follows: $k_{1}=4.8 \mathrm{~min}^{-1} ; k_{-1}=1.92$ $\times 10^{3} \mathrm{~min}^{-1}$. These constants were considered by Maren (42) to be more accurate at $37^{\circ} \mathrm{C}$. Fig. 1 shows a three-dimensional model relating the rate of $\mathrm{H}^{+}$ion production to both intracellular $\mathrm{pH}$ and $\mathrm{PCO}_{2}$ at an $\left[\mathrm{HCO}_{3}\right]_{\mathrm{i}}$ of $25 \mathrm{mM}$. It is clear that the $\mathrm{H}^{+}$ion production by the uncatalyzed reaction increases as a function of intracellular $\mathrm{pH}$ and $\mathrm{PCO}_{2}$. A comparison of $\mathrm{H}^{+}$secretory rates at intracellular $\left[\mathrm{HCO}_{3}\right]_{\mathrm{i}}$ of 15 and $30 \mathrm{mM}$ rather than $25 \mathrm{mM}$ indicated that intracellular $\left[\mathrm{HCO}_{3}\right]_{\mathrm{i}}$ starts to be an important factor, albeit quantitatively minor, only when the intracellular $\mathrm{pH}$ is low, i.e., $<7.00$.

We now examine the predictions of the model in relation to the data obtained in our study during AHC, group C. In group $\mathrm{C}$, arterial $\mathrm{PCO}_{2}$ was $120 \mathrm{mmHg}$ and plasma $\mathrm{tCO}_{2}$ was $32.0 \mathrm{mM}$. Calculated plasma bicarbonate concentration is therefore $28.4 \mathrm{mM}$. The single nephron filtered load of bicarbonate was $1,355 \mathrm{pmol} \cdot \mathrm{min}^{-1}$. To calculate absolute proximal bicarbonate reabsorption from proximal $\mathrm{tCO}_{2}$ concentration of $26.2 \mathrm{mM}$, it is necessary to obtain the exact tubular $\mathrm{PCO}_{2}$ that was not measured in our study. However, we can take two extreme possibilities: (1) tubular $\mathrm{PCO}_{2}$ is higher by $50 \%$ than arterial $\mathrm{PCO}_{2}$, i.e., $\sim 180$ 


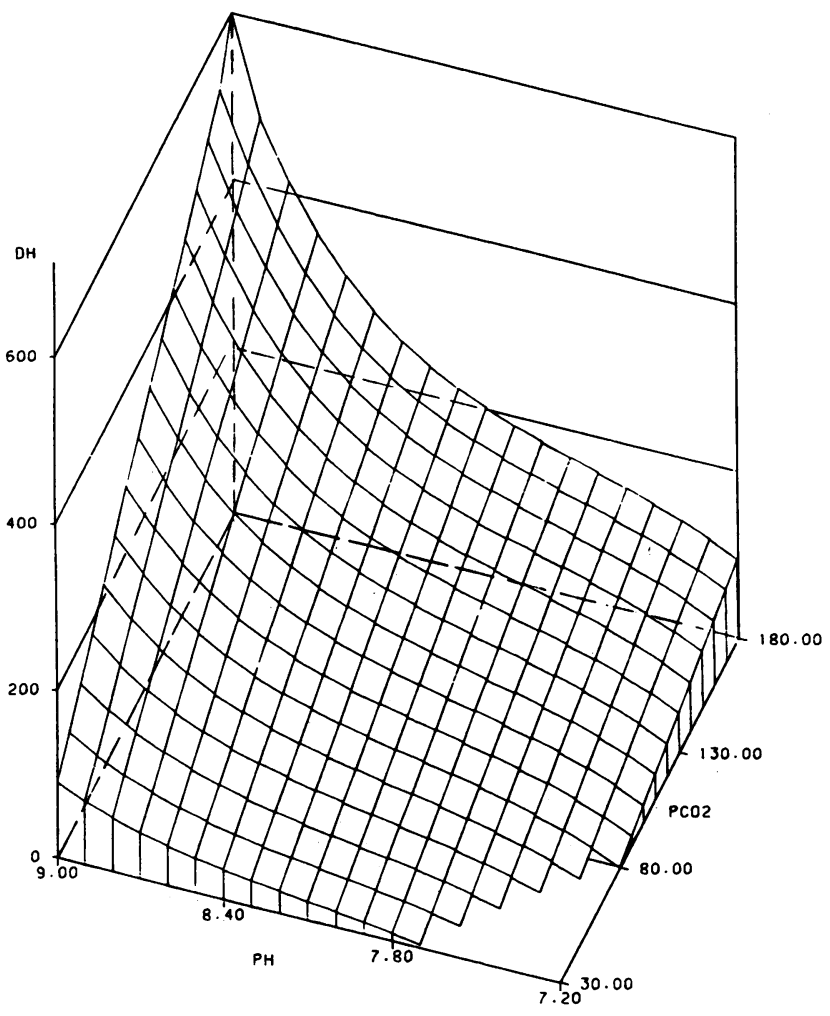

Figure 1. Computer model relating $\mathrm{H}^{+}$secretion $(\mathrm{DH})$ to intracellular $\mathrm{PCO}_{2}$ and $\mathrm{pH}$.

mmHg; (2) tubular $\mathrm{PCO}_{2}$ is identical to arterial $\mathrm{PCO}_{2}$, i.e., $120 \mathrm{mmHg}$. The calculated rates of absolute proximal bicarbonate reabsorption under these conditions are $679 \mathrm{pmol} \cdot \mathrm{min}^{-1}$, at a $\mathrm{PCO}_{2}$ of $180 \mathrm{mmHg}$, and 621 $\mathrm{pmol} \cdot \mathrm{min}^{-1}$, at a $\mathrm{PCO}_{2}$ of $120 \mathrm{mmHg}$.

Assuming that proximal bicarbonate reabsorption is mediated only by $\mathrm{H}^{+}$secretion, our model shows that in order to observe rates of $\mathrm{H}^{+}$ secretion of the magnitude observed in group $\mathrm{C}$, an intracellular $\mathrm{pH}$ over 9.00 at an intracellular $\mathrm{PCO}_{2}$ of either 120 or $180 \mathrm{mmHg}$ is required. Since such extremely alkaline intracellular $\mathrm{pH}$ values of over nine are unlikely, it is clear that during hypercapnia as well as normocapnia (27), an additional source of intracellular $\mathrm{H}^{+}$must exist to account for the observed rate of proximal bicarbonate reabsorption.

\section{Acknowledgments}

The authors are grateful to Dr. F. Wiener for constructing the computer model, and to Jill Scotch and R. Snyder Weiss for their excellent secretarial assistance.

This study was supported by National Institutes of Health grants HL 18875, HL 31485, and AM 17387.

\section{References}

1. Warnock, D. G., and F. C. Rector. 1981. Renal acidification mechanism. In The Kidney. B. M. Brenner and F. C. Rector, Jr., editors. W. B. Saunders Co., Philadelphia. 440-494.

2. Relman, A. S., B. Esteten, and W. B. Schwartz. 1953. The regulation of renal bicarbonate reabsorption by plasma carbon dioxide tension. $J$. Clin. Invest. 32:972-978.
3. Brazeau, P., and A. Gilman. 1953. Effect of plasma $\mathrm{CO}_{2}$ tension on renal tubular reabsorption of bicarbonate. Am. J. Physiol. 175:3338.

4. Dorman, P. J., W. J. Sullivan, and R. E. Pitts. 1954. The renal response to acute respiratory acidosis. J. Clin. Invest. 54:82-90.

5. Rector, F. C., Jr., D. W. Seldin, A. D. Roberts, Jr., and J. S. Smith. 1960. The role of plasma $\mathrm{CO}_{2}$ tension and carbonic anhydrase activity in the renal reabsorption of bicarbonate. J. Clin. Invest. 39:1706-1721.

6. Seldin, D. W., R. M. Portwood, F. C. Rector, and R. Cade. 1959. Characteristics of renal bicarbonate reabsorption in man. J. Clin. Invest. 38:1663-1671.

7. Carter, N. W., D. W. Seldin, and H. C. Teng. 1959. Effect of Diamox on plasma and urine acid base composition during chronic respiratory acidosis. Am. J. Physiol. 196:919-923.

8. Rector, F. C., Jr. 1973. Acidification of the urine. In Handbook of Physiology. Renal Physiology. J. Orloff and R. W. Berliner, editors. American Physiological Society, Washington, DC. 431-454.

9. Cogan, M. G. 1984. Bicarbonate reabsorption in the proximal tubule during carbonic anhydrase inhibition. Ann. NY Acad. Sci. 429: 538-540.

10. Stone, J. E., J. Wells, W. B. Draper, and R. W. Whitehead. 1958. Changes in renal blood flow in dogs during inhalation of $30 \%$ carbon dioxide. Am. J. Physiol. 194:115-119.

11. Farber, A. O., J. J. Szwed, A. R. Dowell, and R. A. Strawbridge. 1976. The acute effects of respiratory and metabolic acidosis on renal function in the dog. Clin. Sci. Mol. Med. 50:165-169.

12. Kittle, C. F., H. Aoki, and E. B. Brown, Jr. 1965. The role of pH and $\mathrm{CO}_{2}$ in the distribution of blood flow. Surgery. 57:139-154.

13. Norman, J. N., J. MacIntyre, J. R. Shearer, I. M. Craigen, and G. Smith. 1970. Effect of carbon dioxide on renal blood flow. Am. J. Physiol. 219:672-676.

14. Anderson, R. J., C. E. Rose, Jr., A. S. Berns, A. L. Erickson, and P. E. Arnold. 1980. Mechanism of effect of hypercapnic acidosis on renin secretion in the dog. Am. J. Physiol. 238:F119-F125.

15. Cogan, M. G., and F. C. Rector, Jr. 1982. Determinants of proximal bicarbonate, chloride and water reabsorption during carbonic anhydrase inhibition. Am. J. Physiol. 242:F274-F284.

16. Shah, P. P., M. LaPointe, C. Sabo, M. Laski, and Y. L. Chan. 1983. Neural regulation of fluid and bicarbonate reabsorption in the rat kidney. Physiologist. 26:A-121.

17. Chan, Y. L. 1980. Adrenergic control of bicarbonate absorption in proximal convoluted tubule of the rat kidney. Pfluegers Arch. Eur. J. Physiol. 388:159-164.

18. Bello-Reuss, E., R. E. Colinders, E. Pastoriza-Munoz, R. A. Mueller, and C. W. Gottschalk. 1975. Effects of acute unilateral denervation in the rat. J. Clin. Invest. 56:208-217.

19. Proll, M. A., C. W. Kamp, and W. W. Morgan. 1982. Use of liquid chromatography with electrochemistry to measure effects of varying intensities of white light on DOPA accumulation in rat retinas. Life Sci. 30:11-19.

20. Pucacco, L. R., and N. W. Carter. 1976. A glass-membrane pH microelectrode. Anal. Biochem. 73:501-512.

21. Richardson, R. M. A., and R. T. Kunau, Jr. 1982. Bicarbonate reabsorption in the papillary collecting duct: effect of acetazolamide. Am. J. Physiol. 243:F74-F80.

22. Vurek, G. G., D. G. Warnock, and R. Corsey. 1975. Measurement of picomole amounts of carbon dioxide by calorimetry. Anal. Chem. 47: 765-767.

23. Duncan, D. B. 1955. Multiple range and multiple F tests. Biometrics. 11:1-42.

24. Giebisch, G., L. Berger, and R. F. Pitts. 1955. The extrarenal response to acute acid-base disturbances of respiratory origin. J. Clin. Invest. 34:231-245.

25. Kurtzman, N. A. 1970. Relationship of extracellular volume and $\mathrm{CO}_{2}$ tension to renal bicarbonate reabsorption. Am. J. Physiol. 219:12991304.

26. DuBose, T. D., Jr., and M. S. Lucci. 1983. Effect of carbonic 
anhydrase inhibition on superficial and deep nephron bicarbonate reabsorption in the rat. J. Clin. Invest. 71:55-65.

27. Cogan, M. G., D. A. Maddox, D. G. Warnock, E. T. Lin, and F. C. Rector, Jr. 1979. Effect of acetazolamide on bicarbonate reabsorption in the proximal tubule of the rat. Am. J. Physiol. 237:F447-F454.

28. DuBose, T. D., Jr., L. R. Pucacco, D. W. Seldin, N. W. Carter, and J. P. Kokko. 1978. Direct determination of $\mathrm{pCO}_{2}$ in the rat renal cortex. J. Clin. Invest. 62:338-348.

29. Levine, D. Z. 1971. Effect of acute hypercapnia on proximal tubular water and bicarbonate reabsorption. Am. J. Physiol. 221:11641170.

30. Malnic, G., M. De Mello Aires, and G. Giebisch. 1972. Micropuncture study of renal tubular hydrogen ion transport in the rat. $\mathrm{Am}$. J. Physiol. 222:147-158.

31. De Mello Aires, M., and G. Malnic. 1975. Peritubular pH and $\mathrm{pCO}_{2}$ in renal tubular acidification. Am. J. Physiol. 228:1766-1774.

32. Cogan, M. G. 1984. Effects of acute alterations in $\mathrm{pCO}_{2}$ on proximal $\mathrm{HCO}_{3}^{-}, \mathrm{Cl}$, and $\mathrm{H}_{2} \mathrm{O}$ reabsorption. Am. J. Physiol. 246:F21-F26.

33. Cogan, M. G., and F. Y. Liu. 1983. Metabolic alkalosis in the rat. J. Clin. Invest. 71:1141-1160.

34. Chan, Y. L., G. Malnic, and G. Giebisch. 1983. Passive driving forces of proximal tubular fluid and bicarbonate transport: gradient dependence of $\mathrm{H}^{+}$secretion. Am. J. Physiol. 245:F622-F633.
35. Aronson, P. S. 1983. Mechanisms of active $\mathrm{H}^{+}$secretion in the proximal tubule. Am. J. Physiol. 245:F647-F659.

36. Alpern, R. J., M. G. Cogan, and F. C. Rector, Jr. 1983. Flow dependence of proximal tubular bicarbonate reabsorption. Am. J. Physiol. 245:F478-F484.

37. Alpern, R. J., M. G. Cogan, and F. C. Rector, Jr. 1982. Effect of luminal bicarbonate concentration on proximal acidification in the rat. Am. J. Physiol. 243:F53-F59.

38. Maren, T. H. 1974. Chemistry of the renal reabsorption of bicarbonate. Can. J. Physiol. Pharmacol. 52:1041-1050.

39. Struyvenberg, A., R. B. Morrison, and A. S. Relman. 1982. Acidbase behavior of separated canine tubule cells. Am. J. Physiol. 214:11551162.

40. Kleinman, J. G., W. W. Brown, R. A. Ware, and J. H. Schwartz. 1980. Cell pH and acid transport in renal cortical tissue. Am. J. Physiol. 239:F440-F444.

41. Maren, T. H. 1978. Carbon dioxide equilibria in the kidney: the problems of elevated carbon dioxide tension, delayed dehydration and disequilibrium pH. Kidney Int. 14:395-405.

42. Aronson, P. S., J. Nee, and M. A. Suhm. 1982. Modifier role of internal $\mathrm{H}^{+}$in activating the $\mathrm{Na}-\mathrm{H}$ exchanger in renal microvillus membrane vesicles. Nature (Lond.). 299:161-163. 